\title{
The Effect of Flunarizine Prophylactic Treatment on Headache Frequency and Plasma Glutamate Levels in Chronic Tension-type Headache Patients
}

\author{
Khairul Putra Surbakti* (D), Hasan Sjahrir \\ Department of Neurology, Faculty of Medicine, Universitas Sumatera Utara, Medan, Indonesia
}

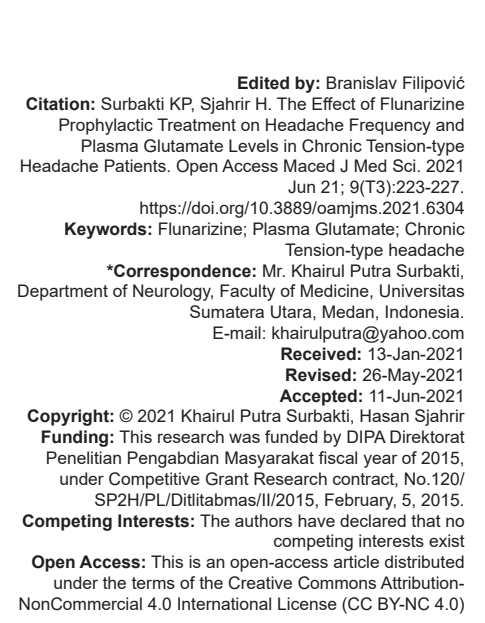

Introduction

Headache is one of the most common neurological disorders interfering with everyday life [1]. Tension-type headache (TTH) is one of the most common in adults among the various forms of headache disorders. Globally, the percentages of the active headache adult population are 46 percent for overall headache, $11 \%$ for migraine, $42 \%$ for stress-type headache, and $3 \%$ for chronic daily headache [2]. A hospital-based study in Indonesia reported the prevalence of episodic TTH and chronic TTH (CTTH) to be 31-24\%, respectively [3]. About $92.0 \%$ of primary headache patients did not use health care and $66.0 \%$ did not use any narcotics or medicines during the acute attacks and no preventive treatment was used [4]. Despite its high prevalence and socioeconomic impact, our understanding of TTH pathogenesis is surprisingly limited. Nociception of pericranial muscles, sensitization of trigeminal nucleus/dorsal horn pain transmission circuits, and dysregulation of central pain control have all been postulated to play a significant role in CTTH pathophysiology [5], [6]. There are no helpful investigations in diagnosing TTH so that the definition relies exclusively on clinical symptoms [7].

The pathogenesis complexity is reflected in the variety of available prophylactic drugs. Prophylactic medications are those drugs that are administered regularly to avoid headache attacks, regardless of whether headache is presently encountered. Tricyclic antidepressant agents, other antidepressants, and muscle relaxants are the most common prophylactic drugs used for CTTH, but benzodiazepines and vasodilator agents are often prescribed. The advantage of antidepressants is still controversial as prophylactic treatment in CTTH [8]. Glutamate stimulation of $\mathrm{N}$-methyl-D-aspartate (NMDA) receptors has been speculated to play a role in primary disorders of headache. Memantine can prevent primary headaches by blocking NMDA receptors and thus inhibiting these pathways [9]. In migraine patients, plasma glutamate level monitoring can serve as a biomarker of response to treatment and as an objective measure of disease status [10]. The molecular mediators by which glutamate works are glutamatergic receptors that are located in the trigeminovascular system and its structures. Within synaptic vesicles, glutamate is intracellularly 
retained where the concentration can be as high as 100 millimolars and is inactive until released into the synapse. The activation of the trigeminovascular system and central sensitization is believed to involve glutamate [11].

Flunarizine was first used in the 1970s for the treatment of occlusive vascular diseases as a longacting calcium channel blocker. The mechanism of action of flunarizine in migraine is unknown, although some insights into potential subcortical brain targets may be provided by its calcium and dopaminergic antagonism. Flunarizine can also cause inhibition of transmission along the trigeminovascular system [12]. Several studies have shown that migraine prophylaxis in adults is effective [13]. However, to our knowledge, there is no publication about its efficacy in CTTH prophylaxis. In this randomized placebo-controlled trial, we aimed to determine: (a) The efficacy of flunarizine in CTTH and (b) the correlation of glutamate levels in CTTH with response to medication.

\section{Methods}

\section{Subjects and procedures}

We studied 19 subjects (Table 1) suffering from CTTH according to the International Classification of Headache Disorders, $2^{\text {nd }}$ edition (ICHD-II, 2004) criteria [14]. CTTH patients were recruited among those attended during June and December 2015, the outpatient clinic of the Adam Malik General Hospital Medan. They were randomized into three interventional groups (flunarizine $5 \mathrm{mg}$, flunarizine $10 \mathrm{mg}$, and placebo). We included both male and female patients between 18 and 65 years old. We excluded CTTH patients receiving or having received a prophylactic treatment in the previous 4 weeks, patients with neurological deficits related to his/ her headache, depression, extrapyramidal disorders, chronic obstructive pulmonary disease (COPD), bronchial asthma, heart failure, diabetes mellitus, cardiovascular disease, malignancy, pregnancy, lactation, and hypersensitive to flunarizine.

Written informed consent, following a detailed explanation of the study procedures and purposes, was obtained from each subject. The study was approved by the Health Research Ethical Committee of North Sumatera/RSUP. H Adam Malik Medan, c/o Medical School, Universitas Sumatera Utara with certificate number 240/KOMET/FK USU/2015. Patients'

Table 1: CTTH characteristics

\begin{tabular}{llll}
\hline Characteristics & $\begin{array}{l}\text { Flunarizine 5 mg } \\
\text { group }(\mathrm{n}=5)\end{array}$ & $\begin{array}{l}\text { Flunarizine 10 } \\
\text { mg group }(\mathrm{n}=5)\end{array}$ & $\begin{array}{l}\text { Placebo } \\
\text { group }(\mathrm{n}=7)\end{array}$ \\
\hline Male & 3 & 0 & 0 \\
Female & 4 & 5 & 7 \\
Mean age \pm SD (years) & $37.86 \pm 9.69$ & $47.20 \pm 11.84$ & $48.43 \pm 11.91$ \\
$\begin{array}{l}\text { Mean headache frequency } \pm \text { SD } \\
\text { (days/month) }\end{array}$ & $8.14 \pm 4.33$ & $10.80 \pm 3.96$ & $8.29 \pm 3.77$ \\
\hline n: Number of patients, SD: Standard deviation, CTTH: Chronic tension-type headache.
\end{tabular}

characteristics were recorded by medical examination, and headache frequency was determined by history taking at the first visit to outpatient clinic Adam Malik General Hospital Medan and taking from headache diary after 8-week prophylactic treatment as the endpoint. Patients with chronic headache-type stress were observed before and after 8 weeks of prophylactic therapy. Venous blood samples for the glutamate concentration assay were taken after completion of the data collection.

\section{Assay of glutamate}

VacutainertubescontainingK2-ethylenediamine tetra-acetic acid were obtained from blood samples. By centrifugation at $1000 \mathrm{~g}$ over $15 \mathrm{~min}$, plasma separation was isolated. Plasma samples should always be 1:5 (100 $\mu$ l serum $+400 \mu$ l water) pre-diluted and processed at $2-80^{\circ} \mathrm{C}$ until the analysis time.

Glutamate concentrations were measured on plasma by means of glutamate enzyme-linked immunosorbent assay (ELISA) Kit KA 1909 Abnova and Chemwell 2910 analyzer. There are three steps of the glutamate assay procedures: Extraction, derivatization, and ELISA. Extraction procedures were performed manually, whereas derivatization and ELISA were done robotically using Chemwell 2910 analyzer. One hundred microliters of the standards, controls, and samples (plasma diluted 1:5) were entered into the required wells of the extraction plate during the extraction step. Then all wells were added with $100 \mu \mathrm{l}$ of the diluent. The plates were coated with adhesive foil and shaken at room temperature for $10 \mathrm{~min}(20$ $250^{\circ} \mathrm{C}$ ) on a shaker at approx. $600 \mathrm{rpm}$ ) and $25 \mu \mathrm{l}$ for subsequent derivatization. Derivatization procedure was initiated by taking $25 \mu \mathrm{l}$ standards, controls, and samples into the appropriate wells of reaction plate. After that, $10 \mu \mathrm{l} \mathrm{NaOH}, 50 \mu \mathrm{l}$ Equalizing Reagent, and $10 \mu \mathrm{l} D$-Reagent were added consecutively into each well followed by covering the plates with adhesive foil and incubating for $2 \mathrm{~h}$ at room temperature $\left(20-25^{\circ} \mathrm{C}\right)$ on shaker (approx. $600 \mathrm{rpm}$ ). Seventy-five microliter Q-Buffer solution was added into all wells followed by shaking for $10 \mathrm{~min}$ at room temperature $\left(20-25^{\circ} \mathrm{C}\right)$ and $25 \mu$ l standards, controls, and samples were used for ELISA. Glutamate ELISA procedure was started by taking $25 \mu \mathrm{l}$ standards, controls, and samples into the appropriate wells of the Glutamate Microtiter Strips. Fifty microliters of glutamate antiserum were added into all wells and mixed shortly. The plates were covered with adhesive foil and incubated $2 \mathrm{~h}$ at room temperature $\left(20-25^{\circ} \mathrm{C}\right)$ on a shaker (approx. $600 \mathrm{rpm}$ ). The plates were washed 3 times by adding $300 \mu \mathrm{l}$ of wash buffer. Both wells were added $100 \mu \mathrm{l}$ of the enzyme conjugate and incubated for $30 \mathrm{~min}$ on a shaker at room temperature $\left(20-250^{\circ} \mathrm{C}\right.$ ) (approx. $600 \mathrm{rpm}$ ). By adding $300 \mu \mathrm{l}$ of the washed buffer, the plates were then washed. One hundred microliters of 
substrate were applied to all wells and incubated on a shaker (approx. $600 \mathrm{rpm}$ ) for 20-30 $\mathrm{min}$ at room temperature $\left(20-250^{\circ} \mathrm{C}\right)$ and $100 \mu \mathrm{l}$ of stop solution was then added to each well and the microtiter plate was shaken to ensure a homogeneous solution distribution. Finally, the solution absorbance in the wells was read at a wavelength between $620 \mathrm{~nm}$ and $650 \mathrm{~nm}$ within 10 min. Limit of detection of Glutamate ELISA Kit, Abnova $\mathrm{KA} 1909$ is $0.3 \mu \mathrm{g} / \mathrm{ml}$ or equals $2.04 \mu \mathrm{mol} / \mathrm{L}$.

\section{Data analysis}

The concentrations of plasma glutamate and the frequency of headaches before and after 8 weeks of prophylactic treatment were compared using the t-dependent paired data test. Variance analysis (ANOVA) was used to assess if the three interventional groups varied significantly (flunarizine $5 \mathrm{mg}$, flunarizine $10 \mathrm{mg}$, and placebo). To determine the most effective drug among the groups, the data analysis was continued by Fisher's least significance difference (LSD) post-hoc testing. All data were expressed as mean \pm SD. $p<0.05$ was considered to be significant.

\section{Results}

Nineteen patients out of 24 initially recruited had completed the study protocol until the end of the study. Of 5 subjects drop out, one female patient discontinued consuming the prophylactic drug given due to allergic reaction, four of them did not come back for the second blood sample after 8 weeks. After 8 weeks of treatment, 19 patients had mean plasma glutamate lower significantly in the flunarizine $5 \mathrm{mg}$ group compared before and after treatment (1.98 \pm 0.92 vs. $1.98 \pm 0.92)(p<0.05$, t-dependent test for paired data). In the flunarizine, $10 \mathrm{mg}$ group, the mean plasma glutamate was also lower significantly compared before and after treatment (1.23 \pm 0.39 vs. $0.37 \pm 0.10)(p<0.05$, t-dependent test for paired data). In the placebo group, the mean plasma glutamate decreased after treatment but did not differ significantly $(2.78 \pm 1.70$ vs. $2.12 \pm 1.32)(p<0.05$, t-dependent test for paired data).

Decreased headache frequency was found in all three groups but to a statistically significant degree (Table 2).

Table 2: Plasma concentration (Mean \pm SD) of glutamate $(\mu \mathrm{g} / \mathrm{L}$ ) and headache frequency (days/month) in CTTH patients, before and after 8-week prophylactic treatment

\begin{tabular}{|c|c|c|c|c|c|c|}
\hline \multirow{2}{*}{$\begin{array}{l}\text { Prophylactic } \\
\text { treatment }\end{array}$} & \multicolumn{2}{|c|}{ Plasma glutamate } & \multirow[t]{2}{*}{$p$} & \multicolumn{2}{|c|}{ Headache frequency } & \multirow[t]{2}{*}{$\mathrm{p}$} \\
\hline & Before & After & & Before & After & \\
\hline Flunarizine $5 \mathrm{mg}$ & $1.98 \pm 0.92$ & $0.52 \pm 0.34$ & $<0.001$ & $8.14 \pm 4.33$ & $3.71 \pm 1.70$ & $<0.001$ \\
\hline Flunarizine $10 \mathrm{mg}$ & $1.23 \pm 0.39$ & $0.37 \pm 0.10$ & $<0.001$ & $10.8 \pm 3.96$ & $4.40 \pm 1.67$ & $<0.001$ \\
\hline Placebo & $2.78 \pm 1.70$ & $2.12 \pm 1.32$ & $<0.37$ & $8.29 \pm 3.77$ & $6.57 \pm 3.60$ & $<0.37$ \\
\hline
\end{tabular}
type headache, SD: Standard deviation.
To determine the difference among the three interventional groups and to find out the most effective drug, we used ANOVA followed by Fisher's LSD post-hoc testing. Figure 1 shows that the mean plasma glutamate in flunarizine $5 \mathrm{mg}$ group was lower significantly than placebo group ( $p<0.001 ; 95 \% \mathrm{Cl}$ : 0.40-1.07). In the flunarizine, $10 \mathrm{mg}$ group, the mean of plasma glutamate was significantly lower compared to placebo group ( $p<0.001 ; 95 \% \mathrm{Cl}$ : 0.53-1.26).

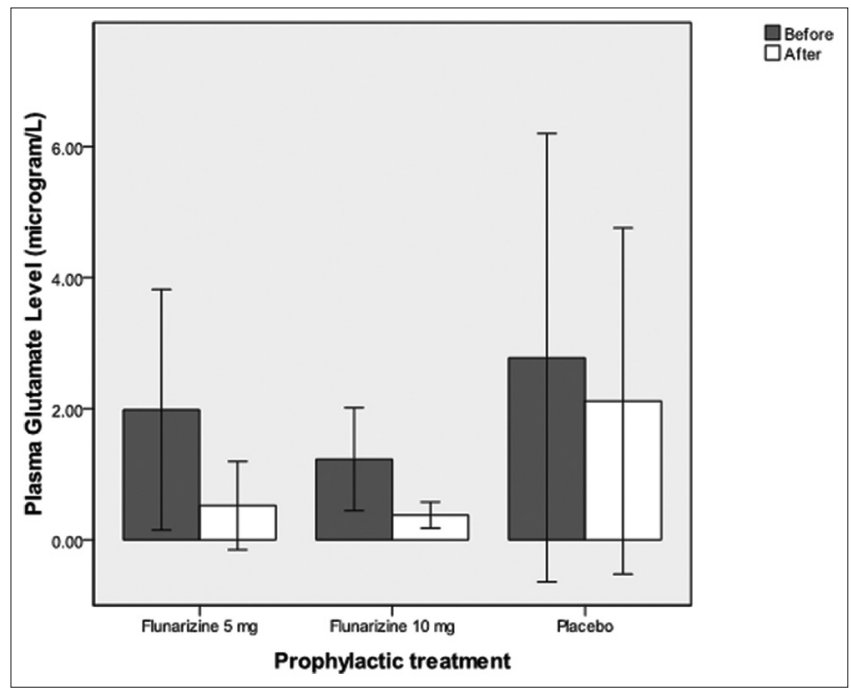

Figure 1: Plasma glutamate concentration (mean $\pm S D$ ) in $(\mu \mathrm{g} / \mathrm{L})$ before (black bar) and after (white bar) 8-week prophylactic treatment in the three interventional groups. There were found significant difference in the flunarizine $5 \mathrm{mg}$ and flunarizine $10 \mathrm{mg}$ groups, while in the placebo group, there was no significant difference. (Before vs. after $p<0.05$ using $t$-dependent test; the difference among the three groups with variance analysis followed by post-hoc analysis using least significance difference test)

There was no statistically significant difference in plasma glutamate concentrations between the flunarizine $5 \mathrm{mg}$ and flunarizine $10 \mathrm{mg}$ groups $(p<0.37$; $95 \% \mathrm{Cl}$ : (0.52-0.21). A reduction of headache frequency in all groups was found after 8-week prophylactic treatment using the t-independent test for paired data. However, there was no statistically difference in headache frequency between the three interventional groups when ANOVA followed by LSD post-hoc testing was performed (Figure 2).

In this study, significant reduction of plasma glutamate levels was followed by headache frequency reduction but not significant statistically. Both flunarizine and placebo did not show significant difference in reducing headache frequency in CTTH. It revealed that there was a lack of correlation of glutamate levels in CTTH with response to prophylactic treatment.

Our findings have shown that successful prophylactic flunarizine therapies have been accompanied by a decrease in plasma glutamate levels and indicate that prophylactic therapies can act on one of the underlying mechanisms that contribute to CTTH causation. However, given the small size of the sample, our data must be interpreted cautiously. 


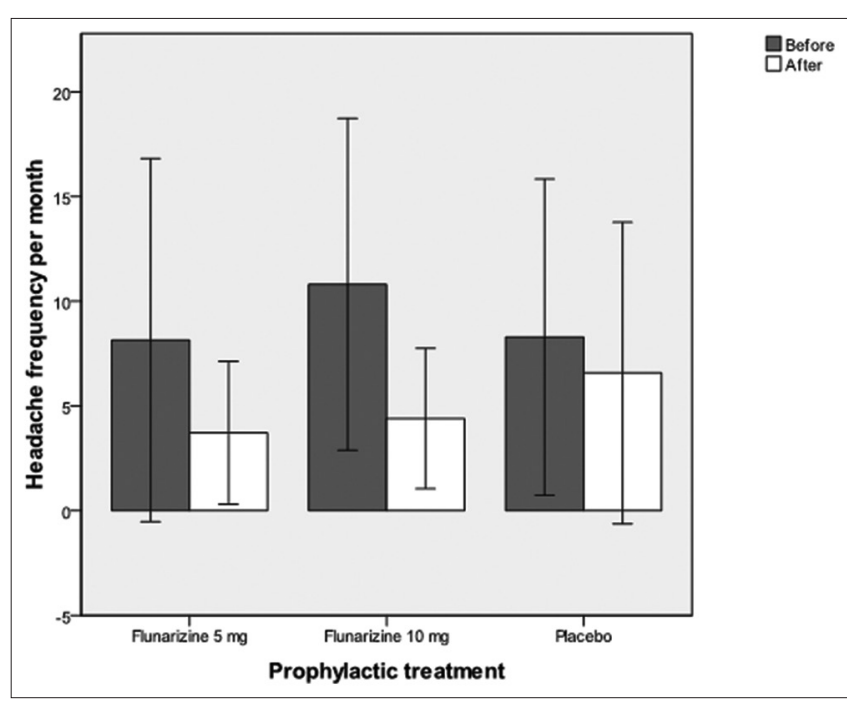

Figure 2: Headache frequency per month (mean $\pm S D$ ) before (black bar) and after (white bar) 8-week prophylactic treatment in the three interventional groups. There was no significant reduction of headache frequency in the three interventional groups. (Before vs. after $p<0.05$ using $t$-dependent test; the difference among the three groups with variance analysis followed by post-hoc analysis using least significance difference test)

\section{Discussion}

In the present study, the usage of flunarizine as prophylactic treatment was followed by reduction of plasma glutamate levels significantly in CTTH patients. Flunarizine, a calcium channel blocker, could inhibit the release of glutamate just blocking voltage-dependent calcium channels [15]. The relationship between flunarizine prophylactic treatment and reduction of plasma glutamate concentration in the present study was more likely an association than a causal one. It is not fully understood the mechanism which makes most prophylactic drugs effective in CTTH. Our findings support the hypothesis that chronic pain or chronic headache states may have a commonality or overlap of signal barrage to the spinal or brain stem. In these clinical situations, the glutamate system might be the point of enhancement or reinforcement of the pain transmission cascade. Flunarizine has the ability to cross blood-brain barrier and could inhibit the release of glutamate just blocking voltage-dependent calcium channel. It blocks calcium influx so that suppresses neuron hyper-excitability result in reducing headache intensity [6], [16].

The reduction of plasma glutamate levels after 8-week prophylactic treatment reveals that flunarizine influences glutamatergic transmission in the pathogenesis of TTH. While glutamate is not thought to pass the blood-brain barrier easily, the amount of glutamate in the blood is associated positively with the level of glutamate in humans in cerebrospinal fluid (CSF). McGale et al. 1977 suggested that it has been shown that the concentration of 13 amino acids in CSF is directly related to the plasma concentration [17].
Alfredsson et al. 1988 found that the serum and CSF levels of glutamate were positively correlated $(r=0.67$, $p<0.05)$ [18]. Thus, to represent the amount of glutamate in the brain per se, the peripheral glutamate level can be postulated. In fact, several neuropsychiatric conditions have reported elevated glutamate plasma levels such as epilepsy [19], Alzheimer's disease [20], and amyotrophic lateral sclerosis [21]; excitotoxicity of glutamate is known to play a role in pathophysiology.

\section{Conclusions}

The usage of flunarizine as prophylactic treatment can reduce plasma glutamate levels significantly in CTTH patients. Either flunarizine or placebo showed no significant difference in reducing headache frequency in CTTH patients.

\section{References}

1. Zebenholzer K, Andree C, Lechner A, Brossner G, Lampl C Luthringshausen $\mathrm{G}$, et al. Prevalence, management and burden of episodic and chronic headaches a cross sectional multicentre study in eight Austrian headache centres. J Headache Pain. 2015;16:531. https://doi.org/10.1186/s10194-015-0531-7 PMid:25990699

2. Stovner LJ, Hagen K, Jensen R, Katsarava Z, Lipton RB, Scher A, et al. The global burden of headache: A documentation of headache prevalence and disability worldwide. Cephalalgia. 2007;27(3):193-210. https://doi. org/10.1111/j.1468-2982.2007.01288.x

PMid: 17381554

3. Sjahrir H. Nyeri Kepala 1. Medan: USU Press; 2004.

4. Mengistu G, Alemayehu S. Prevalence and burden of primary headache disorders among a local community in Addis Ababa, Ethiopia. J Headache Pain. 2013;14:30. https://doi. org/10.1186/1129-2377-14-30

5. Bendtsen L. Central sensitization in tension-type headache possible pathophysiological mechanisms. Cephalalgia. 2000;20(5):486-508. https://doi. org/10.1046/j.1468-2982.2000.00070.x

PMid:11037746

6. Chen Y. Advances in the pathophysiology of tension-type headache: From stress to central sensitization. Curr Pain Headache Rep. 2009;13(6):484-94. https://doi.org/10.1007/ s11916-009-0078-x

PMid: 19889292

7. Sacco S, Ricci S, CaroleiA. Tension-type headache and systemic medical disorders. Curr Pain Headache Rep. 2011;15:438-43. https://doi.org/10.1007/s11916-011-0222-2

8. Verhagen AP, Damen L, Berger MY, Passchier J, Koes BW. Lack of benefit for prophylactic drugs of tension-type headache in adults: A systematic review. Family Pract. 2010;27:151-65. https://doi.org/10.1093/fampra/cmp089

9. Huang L, Bocek M, Jordan JK, Sheehan AH. Memantine for the prevention of primary headache disorders. 
Ann Pharmacother 2014;48(11):1507-11. https://doi. org/10.1177/1060028014548872

PMid:25159002

10. Ferrari A, Spaccapelo L, Pinetti D, Tacchi R, Bertolini A. Effective prophylactic treatments of migraine lower plasma glutamate levels. Cephalalgia. 2008;29(4):423-9. https://doi. org/10.1111/j.1468-2982.2008.01749.x

PMid: 19170689

11. Gasparini CF, Smith RA, Griffiths LR. Biochemical studies of the neurotransmitter glutamate: A key player in migraine. Austin $\mathrm{J}$ Clin Neurol. 2015;2(9):1079.

12. Clauhan S, Devi P, Nidhi. Pharmacological profile of flunarizine: A calcium channel blocker. Int J Innov Pharm Sci Res. 2014;2(6):1260-9.

13. Mohammed BP, Goadsby PJ, Prabhakar P. Safety and efficacy of flunarizine in childhood migraine: 11-year experience with emphasis on its hemiplegic migraine. Dev Med Child Neurol. 2012;54(3):274-7. https://doi. org/10.1111/j.1469-8749.2011.04154.x

PMid:22268377

14. Cousin MD, Nicholls DG, Pocock JM. Flunarizine inhibits both calcium-dependent and -independent release of glutamate from synaptosomes and cultured neurones. Brain Res. 1993;606:22736. https://doi.org/10.1016/0006-8993(93)90989-z

15. International Headache Society. The international classification of headache disorders, $2^{\text {nd }}$ edition. Cephalalgia. 2004;24(Suppl 1):1-160.

PMid:14979299
16. Kataki MS, Kumar KT, Rajkumari A. Neuropsychopharmacological profiling of flunarizine: A calcium channel blocker. Int J PharmTech Res. 2010;2(3):1703-13.

17. McGale EH, Pye IF, Stonier C, Hutchinson EC, Aber GM. Studies of the inter-relationship between cerebrospinal fluid and plasma amino acid concentrations in normal individuals. J Neurochem. 1977;29(2):291-7. https://doi.org/10.1111/j.1471-4159.1977. tb09621.x

PMid:886334

18. Alfredsson G, Wiesel FA, Tylec A. Relationships between glutamate and monoamine metabolites in cerebrospinal fluid and serum in healthy volunteers. Biol Psychiatry. 1988;23(7):68997. https://doi.org/10.1016/0006-3223(88)90052-2 PMid:2453224

19. Martinez M, Frank A, Diez-Tejedar E, Hernanz A. Amino acids concentration in cerebrospinal fluid and serum in Alzheimer disease and vascular dementia. J Neural Transm Park Dis Dement Sect. 1993;6(1):1-9. https://doi.org/10.1007/bf02252617 PMid:8216758

20. Rainesalo S, Keränen T, Palmio J, Peltola J, Oja SS, Saransaari P. Plasma and cerebrospinal fluid amino acids in epileptic patients. Neurochem Res. 2004;29(1):319-24. https://doi. org/10.1023/b:nere.0000010461.34920.0c

PMid:14992292

21. Ilzecka J, Stelmasiak Z, Solski J, Wawrzycki S, Szpetnar M Plasma amino acids concentration in amyotrophic lateral sclerosis patients. Amino Acids. 2003;25(1):69-73. https://doi. org/10.1007/s00726-002-0352-2

PMid:12836061 